\title{
Intelligent Perturb and Observe Based MPPT Approach Using Multilevel DC-DC Converter to Improve PV Production System
}

\author{
Imane Ait Ayad (D), Elmostafa Elwarraki, and Mohamed Baghdadi
}

Faculty of Sciences and Technologies, Cadi Ayyad University, Marrakesh, Morocco

Correspondence should be addressed to Imane Ait Ayad; imaneaitayad@gmail.com

Received 23 November 2020; Revised 25 January 2021; Accepted 2 February 2021; Published 18 February 2021

Academic Editor: Luigi Piegari

Copyright (c) 2021 Imane Ait Ayad et al. This is an open access article distributed under the Creative Commons Attribution License, which permits unrestricted use, distribution, and reproduction in any medium, provided the original work is properly cited.

In this paper, an optimized maximum power point tracking (MPPT) control for a standalone photovoltaic (PV) system using a three-level boost (TLB) converter is introduced. The proposed MPPT method is based on an intelligent perturb and observe algorithm using the artificial neural network (ANN-P\&O) to reduce the oscillations at the maximum power point (MPP). In advance, The ANN provides the values of the voltage and the current at the MPP for any solar irradiance and cell temperature. Based on the provided voltage and current, the $\mathrm{P} \& \mathrm{O}$ algorithm generates the optimal duty cycle of the TLB converter to perfectly track the MPP of the PV generator for different values of cell temperature and sunlight irradiance. Besides, a proportional-integral (PI) controller is added to ensure the TLB capacitor voltage balance. The established ANN-P\&O approach is validated in Matlab/ Simulink and compared to the conventional $\mathrm{P} \& \mathrm{O}$ algorithm under various scenarios: (i) irradiance variations, (ii) temperature variations, and (iii) load variations.

\section{Introduction}

The solar energy is a major contributor in the renewable energies due to its simplicity and capacity. With robust and reliable equipment, photovoltaic modules allow electricity production. In the context of sustainable development, solar energy has always been an essential source of electrical energy. At the end of 2018, it represented $20 \%$ of renewable generation capacity as shown in Figure 1.

Renewable energy production has rapidly developed around the world, due to the rising cost of fossil fuels and a global warming awareness. The idea is to produce electricity at a low cost and environmentally friendly way. Today, renewable energies account for more than $18 \%$ of the total energy consumed in the world and provide more than $20 \%$ of electricity production [1].

Figure 2 shows the PV energy conversion chain diagram. It is a standalone PV system composed of a PV generator, which delivers a DC voltage. The DC-DC converter block is added as an adapter to ensure the maximum power point tracking (MPPT) control and improve the PV energy efficiency. In this paper, a three-level boost (TLB) DC-DC converter is used. The TLB converter presents several advantages as compared to the two-level boost converter (Figure 3 ), low size inductor ( $L$ is divided by 4 ), low inductor current ripple, and reducing switching losses [2].

In the last decade, this type of multilevel DC-DC converters has been widely used and adopted in renewable energy systems due to its simple scheme and good accuracy in order to reduce energy losses and improve the PV production systems. In [3], a TLC converter has been designed and implemented with Golden Section Search based MPPT for a PV system. In [4], the TLC converter has been applied in a three-phase wind energy system on the front of a neutral point clamped inverter. A hybrid traction power supply system has employed a TLB converter in $[5,6]$.

In the literature [7-15], several methods of MPPT control have been presented. There are conventional methods such as perturb and observe ( $\mathrm{P} \& \mathrm{O})$ algorithm, sliding mode (SM) controller, incremental conductance (IC), hill climbing (HC), and intelligent methods. In [7], a detailed review of artificial-intelligence-based MPPT 


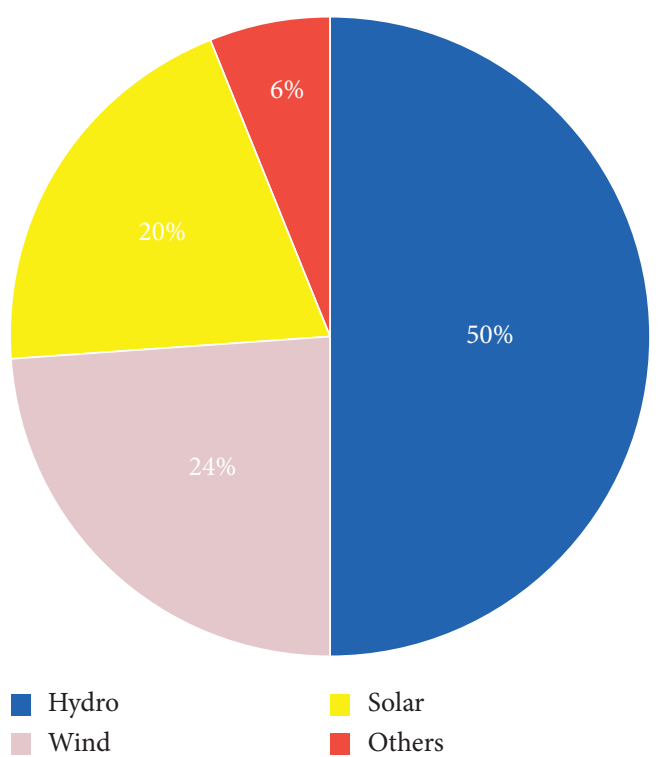

FIGURE 1: Renewable generation capacity by energy source [1].

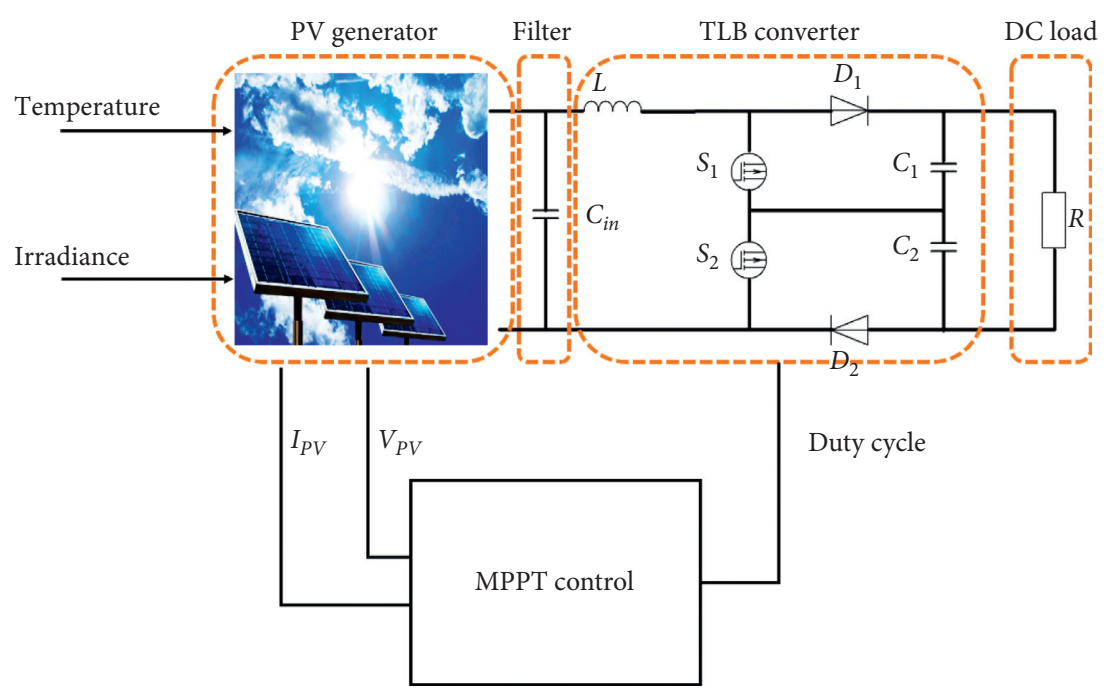

Figure 2: The dealed PV system scheme with MPPT control.

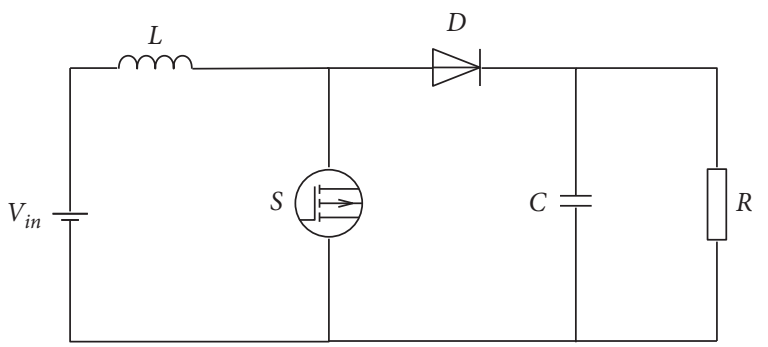

FIGURE 3: Conventional boost DC-DC converter. 
approaches has been presented, such as fuzzy logic (FL) controller, particle swarm optimization (PSO), and artificial neural network (ANN). The authors in [8] have presented the MPPT control using the $\mathrm{P} \& \mathrm{O}$ algorithm for a singleswitch converter in a PV system for solar irradiance variations. This technique is simple and generalized for all PV systems. However, the simulation results have shown that the $\mathrm{P} \& \mathrm{O}$ technique presents the maintained oscillations, which decreases the system stability and efficiency.

In [9], a comparison between P\&O, FL, and SM techniques using a TLB converter was proposed. According to simulation results, the sliding mode controller is the most robust control under irradiance and load changes. However, it is hard to choose a sliding surface and conceive a suitable sliding controller. The researchers of [10] have introduced a FL controller with MIN-MAX fuzzy method applied for PV system using a TLB converter. This controller has been compared to PO, PI, and PSO controllers. The simulation has been made only for variable irradiance neglecting the temperature and load variations. The proposed FL controller can reduce the oscillations, overshoot, and undershoot compared to other controllers. However, it is difficult to choose the input and output gains of the FL controller. In $[11,12]$, the authors have presented a modified incremental conductance algorithm using a conventional boost converter. The novel IC algorithm allows overcoming the wrong decision made by the conventional IC algorithm when the irradiance increases. The proposed algorithm has been made for variable irradiance. The power responses present an oscillating dynamic regime. In [13], a modified IC algorithm has been introduced to track the global maximum power point for a PV system under partial shading conditions. In [14], the authors have proposed an intelligent control based on the ANN using a boost DC-DC converter. The simulation results have proved that the ANN is accurate and can identify the suitable duty cycle under different solar irradiance. In [15], an ANN controller for MPPT control has been proposed. A comparison with the $\mathrm{P} \& \mathrm{O}$ algorithm has been done in terms of power efficiency and oscillations around the MPP.

Previous references have used intelligent methods to improve the conventional techniques' performance by reducing overshoot and steady-state oscillations. In [16], an optimized HC-based MPPT technique by PSO for PV system has been presented. The simulation and experimental results have shown that the tracking is very fast for any step changes in the irradiation and the steady-state oscillations are reduced. The authors have presented a hybrid MPPT technique that combines differential evolution and PSO [17]. The proposed method has shown significant advantages under partial shading conditions. An adaptive P\&O-fuzzy controller for tracking the MPP for boost DC-DC converter in PV system has been proposed by [18]. In [19], a FL has been used to improve the IC technique performance.
Besides, several works have been focused on improving the conventional $\mathrm{P} \& \mathrm{O}$ algorithm. In [20], the authors have presented a hybrid MPPT algorithm that combines PSO and the $\mathrm{P} \& \mathrm{O}$ algorithm. The $\mathrm{P} \& \mathrm{O}$ locates the nearest local maximum point. Then, the PSO determines the MPP. In [21], the authors have combined FL and P\&O algorithm. Initially, FL is used to locate the MPP region. Then, the $\mathrm{P} \& \mathrm{O}$ algorithm is used to perfectly track the MPP. The simulation results have demonstrated that the hybrid algorithm is able to provide higher power than the FL controller and presents a faster dynamic response than the $\mathrm{P} \& \mathrm{O}$ algorithm. However, the weakness of this method is the oscillations during steady state. In [22], an intelligent MPPT algorithm using $\mathrm{P} \& \mathrm{O}$ control optimized by an ANN has been just simulated under varying irradiance conditions. The ANN is used to estimate the $\mathrm{PV}$ voltage variation $\Delta V$ of the $\mathrm{P} \& \mathrm{O}$. Among the limitations of this method, the ANN is conceived based on a mathematical model.

Therefore, this study aims to design easily an efficient method, which allows perfectly following the MPP while respecting the performance criteria of a system, that is, a power response without oscillations, a fast dynamic regime, and a very good precision. Besides, to reduce energy system losses, a TLB converter will be used.

The proposed method is a hybrid approach that combines the conventional $\mathrm{P} \& \mathrm{O}$ technique and the artificial neural network (ANN-P\&O). The ANN is developed to determine, for each operating point (specified irradiation and temperature), the voltage and the current at MPP. The $\mathrm{P} \& \mathrm{O}$ algorithm employs these values to generate the suitable duty cycle of the TLB converter to recuperate the maximum power with good precision under varying climatic conditions and to improve PV production efficiency. Then, to prove the ANN-P\&O approach's efficiency, a comparison with the $\mathrm{P} \& \mathrm{O}$ algorithm is done. Finally, the capacitor voltage balance of the TLB converter is ensured using a proportional-integral (PI) controller.

In order to validate the proposed approach's effectiveness, the ANN-P\&O and the PI controller are simulated using Matlab/Simulink. The simulation results are presented to highlight the great performance of the proposed method. The simulation is presented via three scenarios: (i) temperature variations and constant irradiation, (ii) irradiance variations and constant temperature, and (iii) load variations.

\section{Photovoltaic Generator Model}

Figure 4 represents the simplest equivalent circuit of a solar cell, which is modeled by a current source in parallel with a diode $D$ and a resistor $R_{P}$, which reflects the leakage current in the junction. The series resistor $R_{S}$ represents the resistance of the material and the semiconductor.

The PV cell current $(I)$ is given by the following equation: 


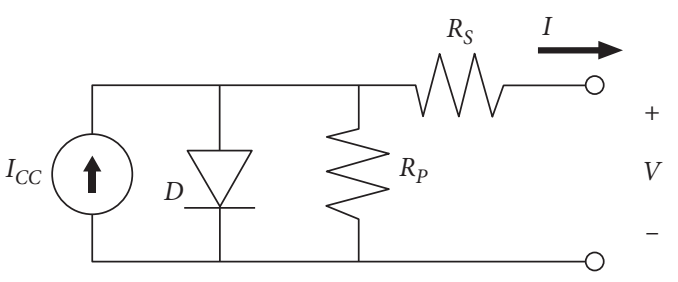

FIgURE 4: Equivalent circuit of PV cell.

$$
I=I_{\mathrm{CC}}-I_{0}\left[e^{q\left(V+R_{S} I / n K T\right)}-1\right]-\frac{V+R_{S} I}{R_{P}},
$$

where $I_{\mathrm{CC}}(A)$ is the cell short-circuit current depending on solar irradiance and cell temperature; $I_{0}(A)$ is the cell reverse saturation current; $K(1.381 \times 10-23 \mathrm{~J} / \mathrm{K})$ is Boltzmann's constant; $T(K)$ is the cell effective temperature; $q(1.602 \times$ $10-19 \mathrm{C}$ ) is the electron charge; $n$ is the nonideality factor of the diode junction; $I(A)$ is the supplied cell current; and $V$ $(V)$ is the cell voltage.

The parallel resistance $R_{P}$ is very high compared to series resistance $R_{S}$. Hence, it can be neglected, and the simplified model is shown in Figure 5. The resulting equation is given as follows:

$$
I=I_{\mathrm{CC}}-I_{0}\left[e^{q\left(V+R_{S} I / n K T\right)}-1\right]
$$

The PV panel consists of interconnecting several cells in series and/or in parallel to achieve the desired power. The used PV panel parameters are presented in Table 1. Figures 6 and 7 show the variations of the power depending on the voltage for different solar irradiance and cell temperature values, respectively. It can be seen that the characteristics are influenced by climate changes, which mark clearly the PV panel nonlinearity. For each irradiance and temperature, a maximum power point (MPP) is specified (VMPP, IMPP, and PMPP), where VMPP, IMPP, and PMPP are the voltage, the current, and the power at MPP, respectively.

\section{Three-Level Boost Converter}

The electrical circuit of the TLB converter is represented in Figure 2; two switches $S_{1}$ and $S_{2}$, two diodes $D_{1}$ and $D_{2}$, and a single inductor $L$ are used. The converter frequency is noted as $f ; d_{1}\left(d_{2}\right)$ is the $S_{1}\left(S_{2}\right)$ duty cycle. The switches command signals are delayed by a half-period [23].

The TLB converter voltage gain is given by the following equation:

$$
V_{\text {out }}=\frac{V_{\text {in }}}{1-d}
$$

where $d=d_{1}=d_{2}, V_{\text {in }}$ is the input voltage, and $V_{\text {out }}$ is the output converter voltage.

The inductor current and the output voltage ripples are written as in the following equations:

$$
\begin{aligned}
& \text { For } d<0,5,\left\{\begin{array}{l}
\Delta V_{\text {out }}=\frac{V_{\text {in } 1-2 d}}{R C f 1-d} \\
\Delta i_{L}=\frac{V_{\text {in }} 1-2 d d}{2 L f 1-d}
\end{array}\right. \\
& \text { For } d>0,5, \quad\left\{\begin{array}{l}
\Delta V_{\text {out }}=\frac{V_{\text {in }} 2 d-1}{R C f 1-d} \\
\Delta i_{L}=\frac{2 d-1 V_{\text {in }}}{2 L f}
\end{array}\right.
\end{aligned}
$$

where $R$ is the load and $C_{1}$ and $C_{2}$ are the output converter capacitors $\left(C_{1}=C_{2}=C\right)$.

Table 2 presents a comparison between TLB and conventional boost converters. According to the comparison, the TLB converter is recommended for renewable energy applications due to its reducing volume, cost, and system complexity.

\section{Hybrid Artificial Neural Network-Perturb and Observe Based MPPT}

The MPPT control is a simple electrical approach that mainly relies on power electronics based on DC-DC converters. The MPPT control is a very powerful tool for optimizing the photovoltaic power system and ensuring good operation in varying climatic conditions. It is generally based on the duty cycle variation of the DC-DC converter in order to follow the MPP.

In this work, a hybrid ANN-P\&O approach is proposed based on the ANN and P\&O algorithm using the TLB converter. The ANN is opted due to its great flexibility and higher reliability. The latter determines, for each operating point (specified solar irradiation and cell temperature), the voltage and current at MPP. Then, a PV system operating point is defined. Based on the provided values, the $\mathrm{P} \& \mathrm{O}$ algorithm generates the suitable duty cycle to coincide with the MPP and recuperate the maximum power with a good precision under varying climatic conditions. Thereafter, the proposed approach is compared to the conventional $\mathrm{P} \& \mathrm{O}$. A proportional-integral (PI) controller is used to ensure the capacitor voltage balance. Finally, the power switches $S_{1}$ and $S_{2}$ are controlled independently to realize the control objectives. The switch command signals are delayed by a half-period. The established control scheme is presented in Figure 8. 


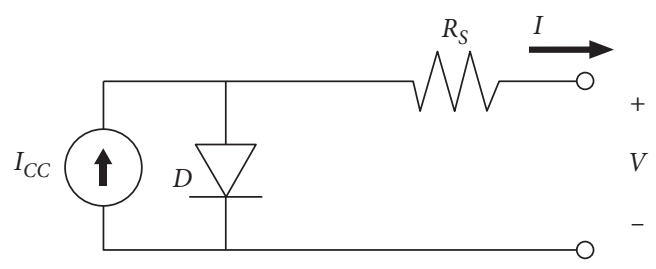

Figure 5: Simplified circuit of PV cell.

TABle 1: PV system parameters.

\begin{tabular}{lc}
\hline Parameter value & Value \\
\hline Maximum power & $220.4 \mathrm{~W}$ \\
Voltage at MPP & $29 \mathrm{~V}$ \\
Current at MPP & $7.6 \mathrm{~A}$ \\
Open-circuit voltage & $36.2 \mathrm{~V}$ \\
Short-circuit current & $8.05 \mathrm{~A}$ \\
Shunt resistance & $236.9 \Omega$ \\
Series resistance & $0.38 \Omega$ \\
\hline
\end{tabular}

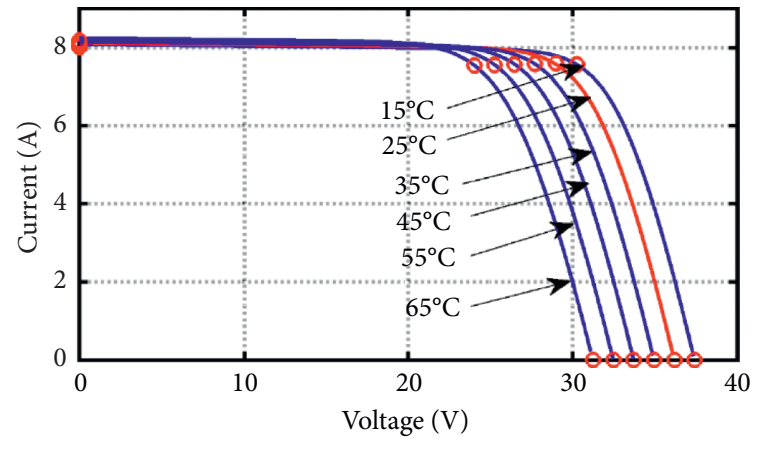

(a)

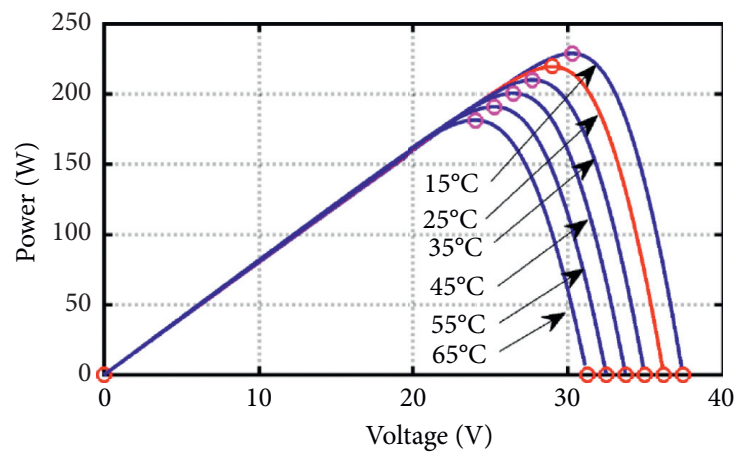

(b)

Figure 6: Characteristics of used PV panel at $1000 \mathrm{~W} / \mathrm{m}^{2}$ for different temperatures. (a) $I-V$ curves. (b) $P-V$ curves.

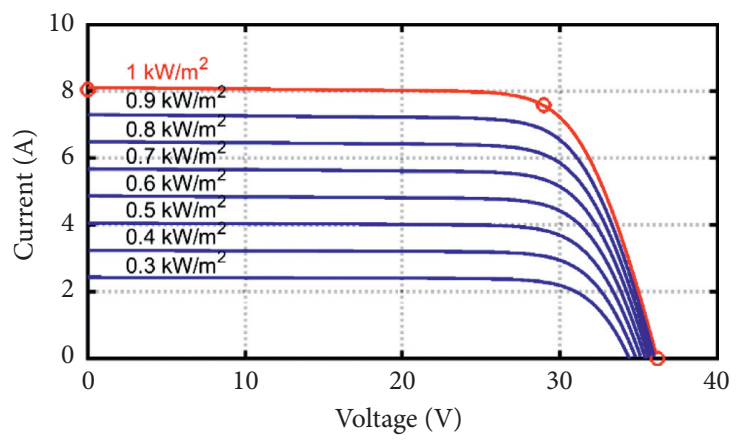

(a)

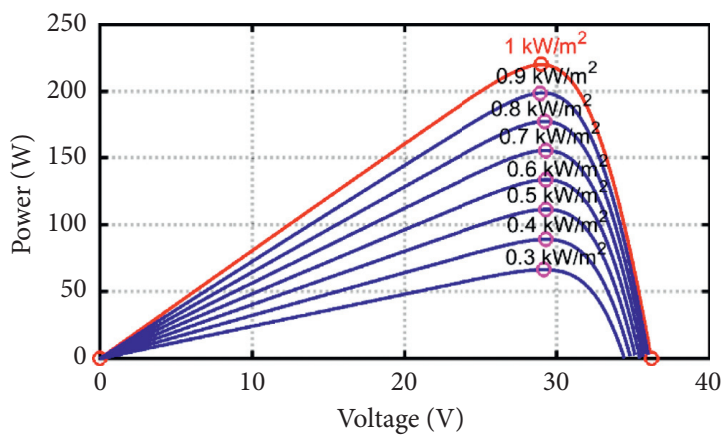

(b)

Figure 7: Characteristics of used PV panel at $25^{\circ} \mathrm{C}$ for different irradiances. (a) $I-V$ curves. (b) $P-V$ curves.

4.1. Design of Artificial Neural Network. An artificial neural network (ANN) is a system based on the biological neural network operation. It is an emulation of the biological neural system. The ANN has been developed to solve control problems of decision and memorization as an alternative to artificial intelligence; it is one of the most reputed techniques among all soft computing techniques [7]. A neural network is composed of several layers (Figure 9): input layer receiving the data to be processed, hidden layer for network treatment, and output layer presenting the network responses. The ANN is widely used for MPPT control, since it does not require a physical model and any complex mathematical 
TABLE 2: Comparative expressions between TLB and boost converters.

\begin{tabular}{lcc}
\hline Converter expressions & Conventional boost converter & TLB converter \\
\hline Switch voltage stress $V_{\text {Smax }}$ & $\left(V_{\text {in }} / 1-d\right)+\left(\Delta V_{\text {out }} / 2\right)$ & $\left(V_{\text {in }} / 1-d\right)+\left(\Delta V_{\text {out }} / 4\right)$ \\
Diode voltage stress $\left.V_{\text {Dmax }} / 2\right)$ & $\left(V_{\text {in }} / 1-d\right)+\left(\Delta V_{\text {out }} / 2\right)$ & $\left(V_{\text {in }} / 1-d\right)+\left(\Delta V_{\text {out }} / 4\right)$ \\
Inductor L & $\left(V_{\text {in }} / 4 \Delta i_{L \text { max }} \cdot f\right)$ & $\left(V_{\text {in }} / 16 \Delta i_{L \text { max }} \cdot f\right)$ \\
\hline
\end{tabular}

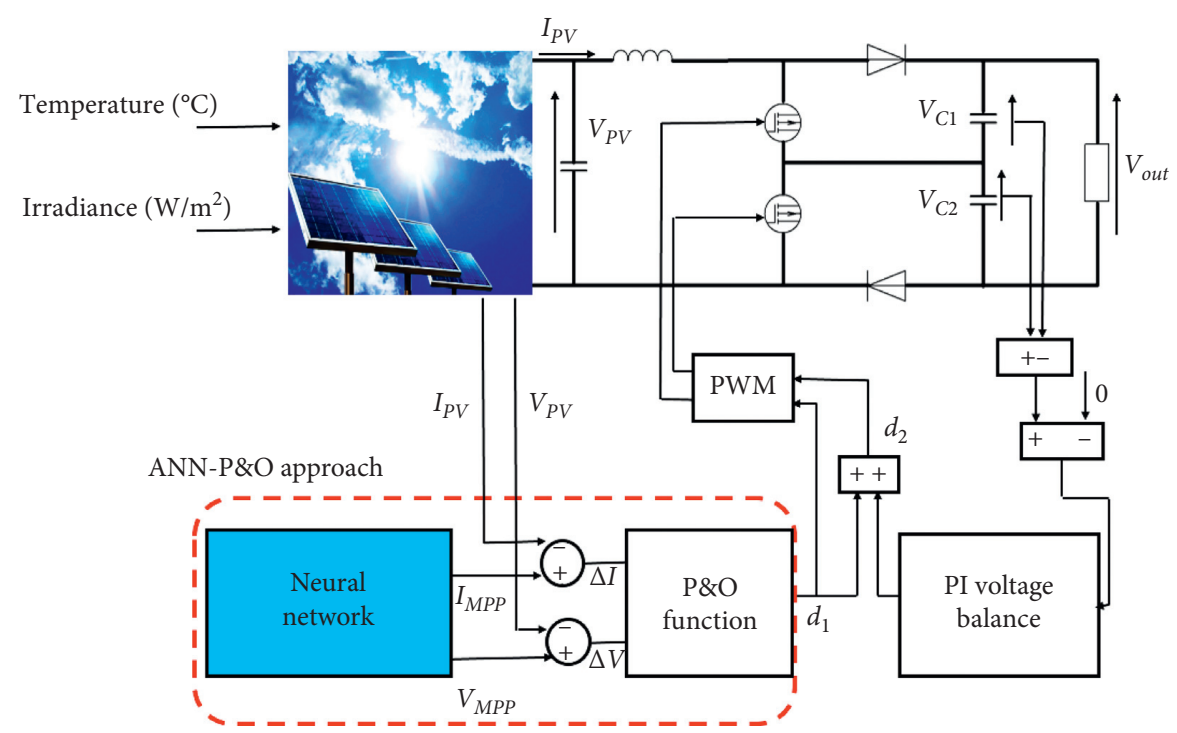

Figure 8: The intelligent MPPT control using the ANN-P\&O approach.

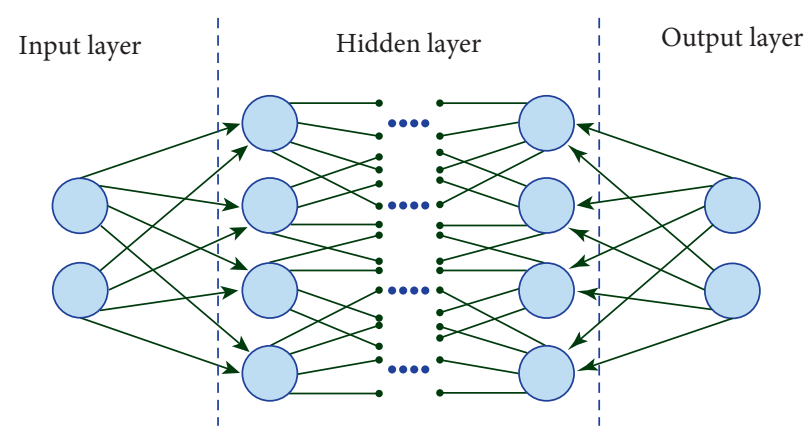

FIgURE 9: Neural network structure.

functions. Moreover, it is able to deal with the high nonlinearities in the $\mathrm{P} / \mathrm{V}$ characteristics of $\mathrm{PV}$ panel [24]. On the other hand, the ANN-based MPPT methods need just a microcontroller/DSP for implementation [25]. A limitation of the ANN is that it needs a big amount of training data to acquire suitable results.

To conceive the proposed ANN, it is necessary to start by defining a learning base as presented in Table 3, using the $P$ / $V$ and $I / V$ characteristics under temperature and irradiance variations. Thereafter, the irradiance and temperature are used as inputs of the proposed ANN, 20 hidden layers are chosen, and voltage and current at the MPP are defined as outputs (Figure 10). Then, the Levenberg-Marquardt backpropagation algorithm is used to train the ANN and fit the inputs and the outputs. The designed ANN can derive the maximum voltage and current for any irradiation and temperature despite the load variations. The provided current and voltage are used as input data by the $\mathrm{P} \& \mathrm{O}$ algorithm.

4.2. Perturb and Observe Method. This method is among the most used conventional ones. The principle of the conventional $\mathrm{P} \& \mathrm{O}$ algorithm consists of perturbing the $\mathrm{PV}$ voltage $\left(V_{\mathrm{PV}}\right)$ and observing the variation of $\mathrm{PV}$ power $\left(P_{\mathrm{PV}}\right)$, if an increase of the voltage generates an increase of the power that means a convergence towards the maximum power zone; on the other hand, if the power decreases, the voltage must be reduced to coincide with the MPP. Figure 11 presents the P\&O flowchart, where $d$ is the TLB converter's duty cycle and $\Delta d$ is the duty cycle variation. The modified $\mathrm{P} \& \mathrm{O}$ algorithm is based on a comparison of $P_{\mathrm{PV}}$ with $P_{\mathrm{MPP}}$. 
TABLE 3: Example of used learning base.

\begin{tabular}{lccc}
\hline Irradiance $\left(\mathrm{W} / \mathrm{m}^{2}\right)$ & Temperature $\left({ }^{\circ} \mathrm{C}\right)$ & VMPP $(\mathrm{V})$ & IMPP $(\mathrm{A})$ \\
\hline 1000 & 25 & 29 & 7.6 \\
1000 & 45 & 27 & 7.58 \\
800 & 25 & 28.8 & 6.5 \\
1000 & 35 & 28 & 7.6 \\
600 & 25 & 26 & 7.6 \\
400 & 25 & 24 & 7.6 \\
\hline
\end{tabular}

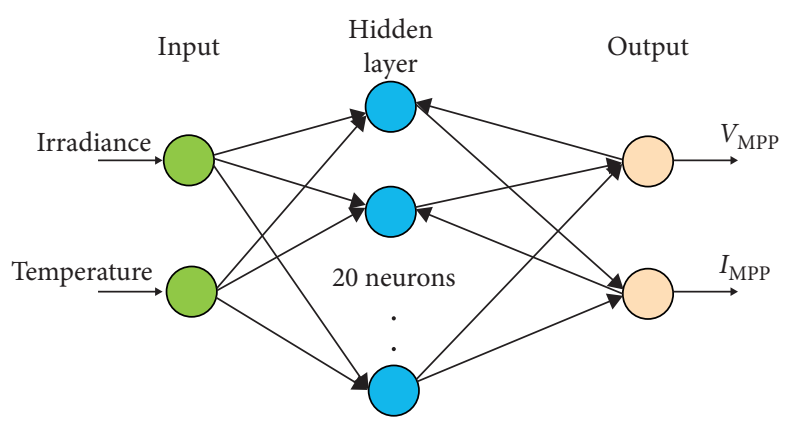

FIGURE 10: The designed neural network layers.

Then, $V_{\mathrm{PV}}$ is reduced or increased to coincide with the MPP. Figure 12 represents the proposed $\mathrm{P} \& \mathrm{O}$ flowchart. The possible cases of the modified algorithm are reduced compared to the classic $\mathrm{P} \& \mathrm{O}$ algorithm.

\section{Simulation and Results}

The simulation is realized with a user-defined PV module in Matlab/Simulink. The PV panel is configured to have the same characteristics as our panel laboratory. Table 4 represents TLB parameters. To validate the ANN-P\&O approach and PI voltage balance, three scenarios are used: varying temperature, varying irradiation, and varying load. In order to show the higher performance of the proposed approach, the simulation results are compared to the conventional $\mathrm{P} \& \mathrm{O}$ algorithm.

In the first scenario, the proposed MPPT control is simulated for different cell temperatures $\left[25^{\circ} \mathrm{C}, 35^{\circ} \mathrm{C}\right.$ (at $t=1 \mathrm{~s}$ ), $45^{\circ} \mathrm{C}$ (at $\left.t=2 \mathrm{~s}\right), 65^{\circ} \mathrm{C}$ (at $t=3 \mathrm{~s}$ ), and $25^{\circ} \mathrm{C}$ (at $t=4 \mathrm{~s})$ ], constant solar irradiance $1000 \mathrm{~W} / \mathrm{m}^{2}$, and $R=100 \Omega$.

According to Figure 13(a), it can be seen that the PV voltage controlled by the ANN-P\&O approach perfectly follows $V_{\text {MPP }}$ from one temperature to another without any oscillation, with higher precision and stability, compared to the conventional $\mathrm{P} \& \mathrm{O}$ algorithm.

Figure 13(b) represents the PV current response. As the PV voltage, the current clearly follows $I_{\mathrm{MPP}}$. For the $\mathrm{P} \& \mathrm{O}$ algorithm, the PV current presents continuous oscillations around $I_{\mathrm{MPP}}$.

Figure 13(c) represents the PV power curve, and the measured power perfectly follows the maximum power without any oscillation and with great precision. Moreover, the output capacitor voltage balance is always ensured as shown in Figure 14.
Figure 15(a) shows the PV current response in the proposed MPPT method and conventional PO algorithm. For ANN-P\&O algorithm, it can be seen that the PV current follows $I_{\text {MPP }}$ from one irradiance to another without any overshot, undershot, and oscillations. Moreover, PV voltage achieves $V_{M P P}$ with neglected oscillations and overshot (Figure 15(b)).

In addition, the PV power perfectly achieves the maximum power, and the output capacitor voltage balance is always ensured as shown in Figures 15(c) and 16, respectively.

The simulation results prove the proposed approach's superiority over the conventional P\&O. The steady-state oscillations and overshot are significantly reduced for temperature and irradiance variations.

In the last scenario, the proposed approach is simulated for variable load $R[10 \Omega, 40 \Omega$, and $100 \Omega]$.

Figures 17 and 18 show the PV power controlled by the ANN-P\&O algorithm for load variations. In the two cases $\left(1000 \mathrm{~W} / \mathrm{m}-25^{\circ} \mathrm{C}\right.$ and $\left.1000 \mathrm{~W} / \mathrm{m}-45^{\circ} \mathrm{C}\right)$, the power maintains its maximum value with good precision.

Like the two previous scenarios, the simulation results have proved the reliability and flexibility of the ANN-P\&O approach to achieve the maximum power, with neglected oscillations, and good performance in static and dynamic regimes with load variations. Table 5 presents a comparison between $\mathrm{P} \& \mathrm{O}, \mathrm{ANN}$, and the proposed hybrid controller in terms of the tracking efficiency and oscillations level. As presented, the proposed method successfully outcomes the shortages of P\&O algorithm and ANN alone. Moreover, Table 6 lists a comparison between the proposed method and other hybrid $\mathrm{P} \& \mathrm{O}$ techniques introduced in the literature in terms of the oscillation level and tracking efficiency. 


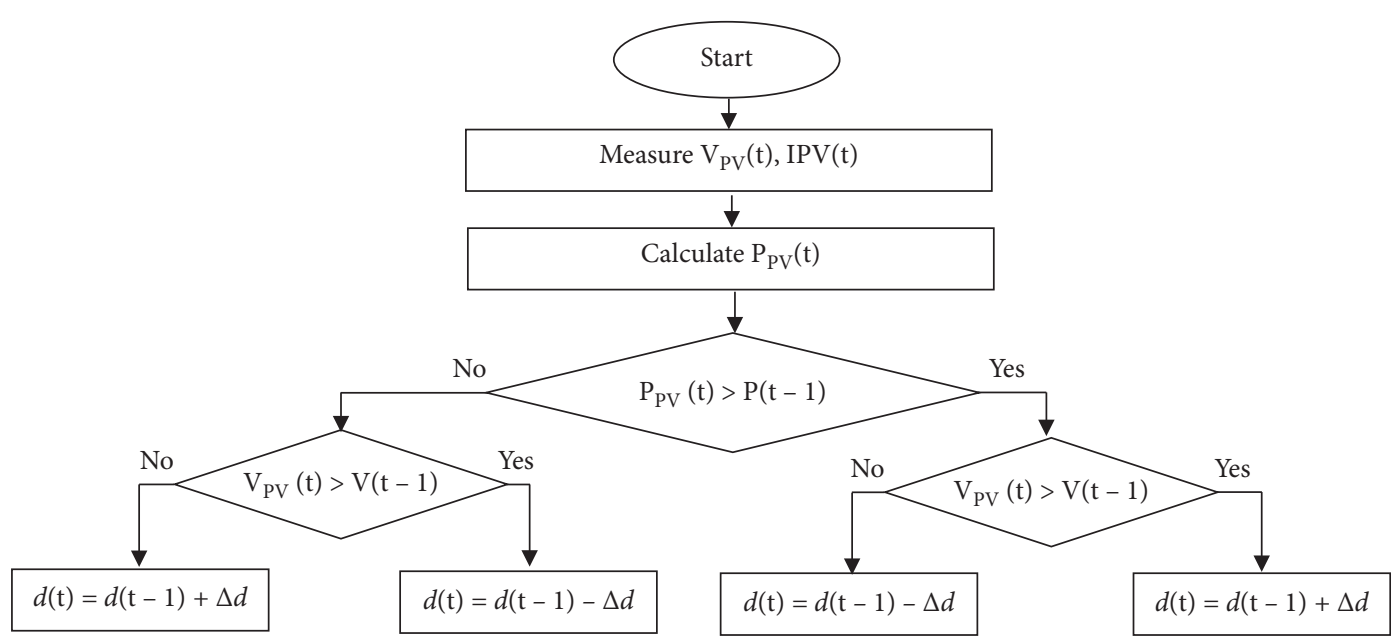

Figure 11: Flowchart of the P\&O algorithm.

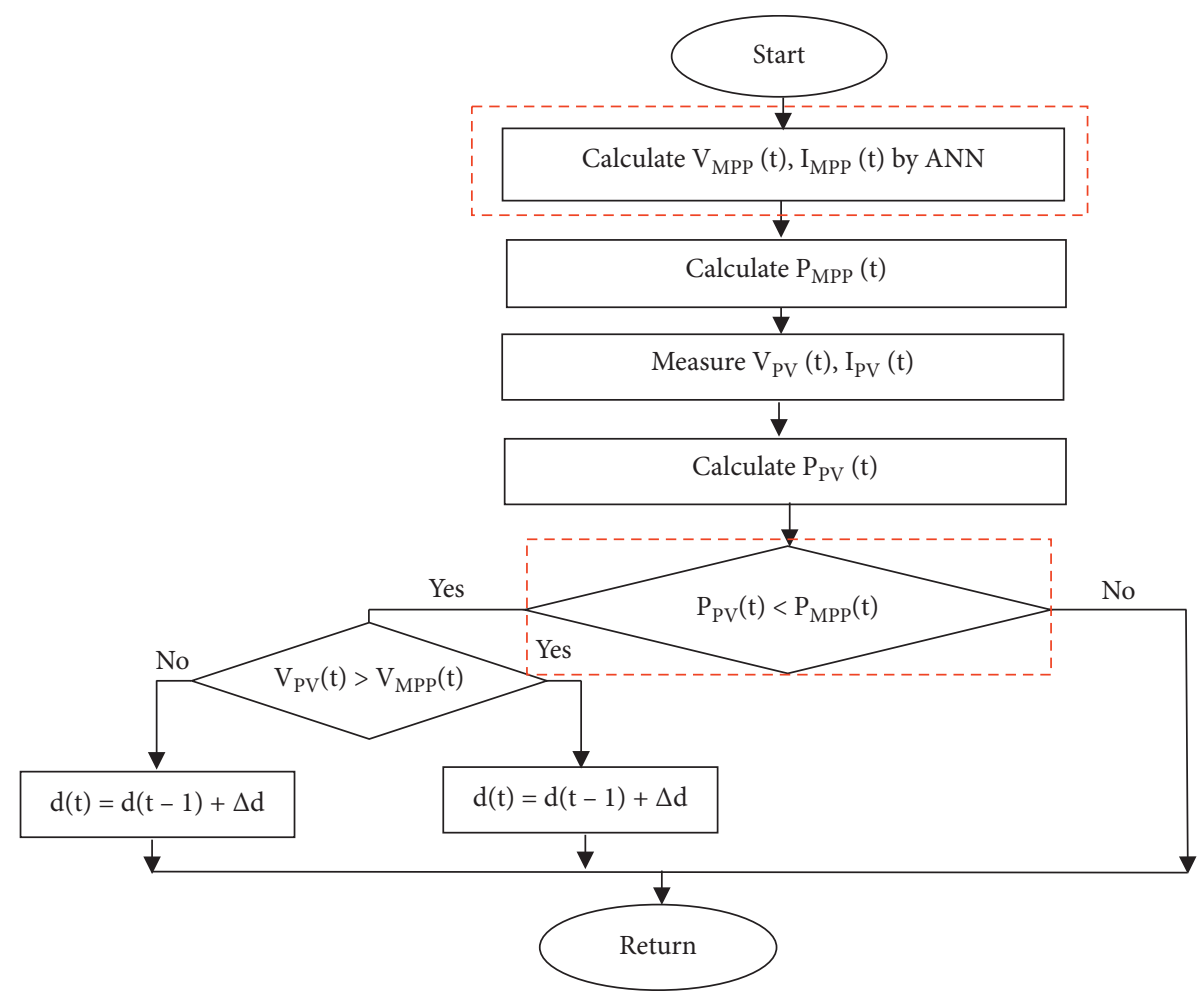

Figure 12: Flowchart of the proposed P\&O algorithm.

TABLE 4: Three-level boost converter parameters.

\begin{tabular}{lc}
\hline Parameter values & Value \\
\hline$C_{\text {in }}$ & $70 \mu \mathrm{F}$ \\
$C_{2}, C_{1}$ & $700 \mu \mathrm{F}$ \\
$R$ & $10 \Omega$ to $100 \Omega$ \\
$L$ & $10 \mathrm{mH}$ \\
$R$ & $0.25 \mathrm{~m} \Omega$ \\
$f$ & $10 \mathrm{kHz}$ \\
\hline
\end{tabular}

$R$ is the output load, $r$ represents the inductor equivalent series resistance, and $C_{i n}$ is the input filter capacitor. 


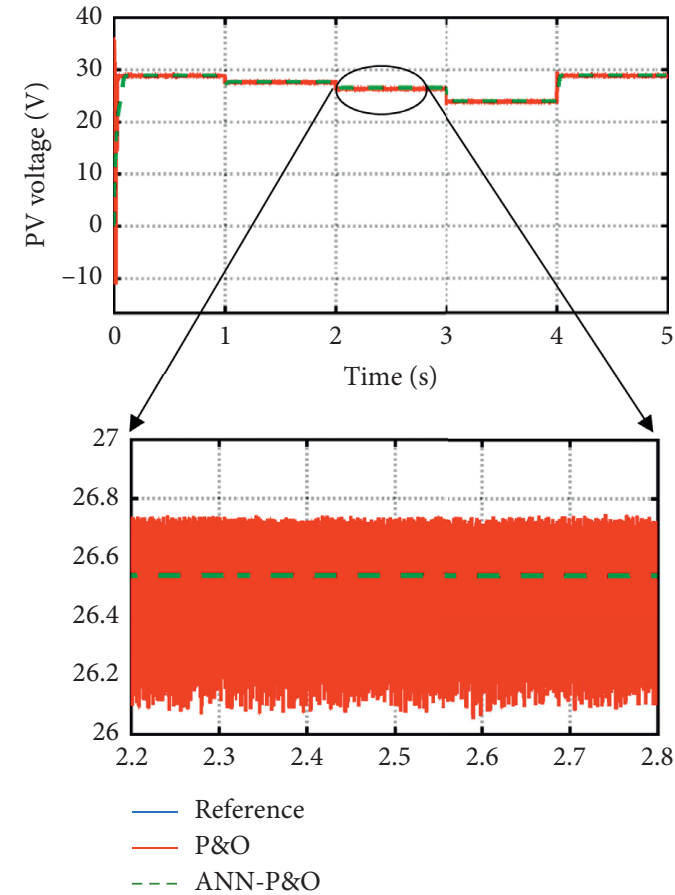

(a)

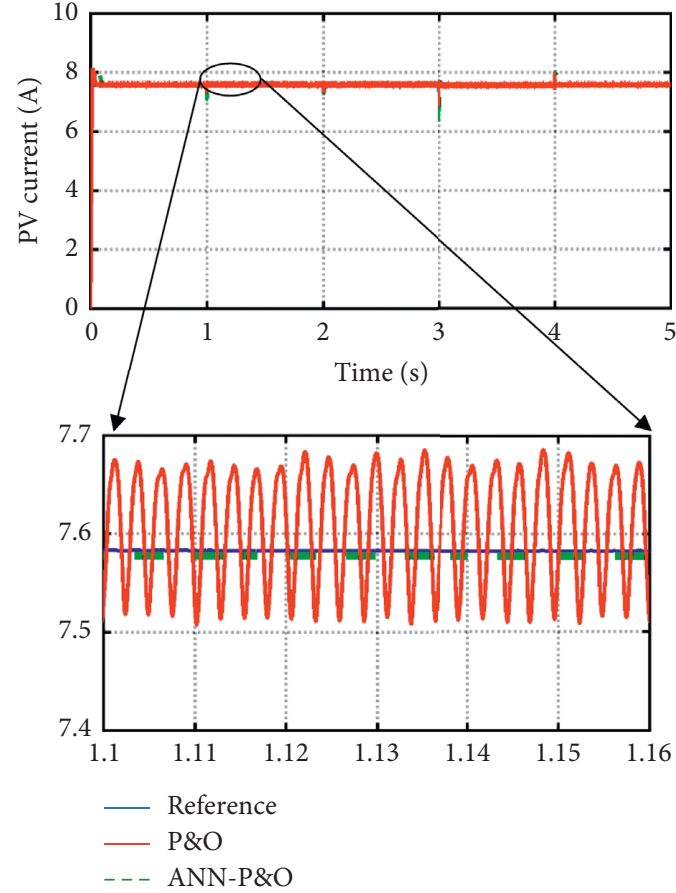

(b)

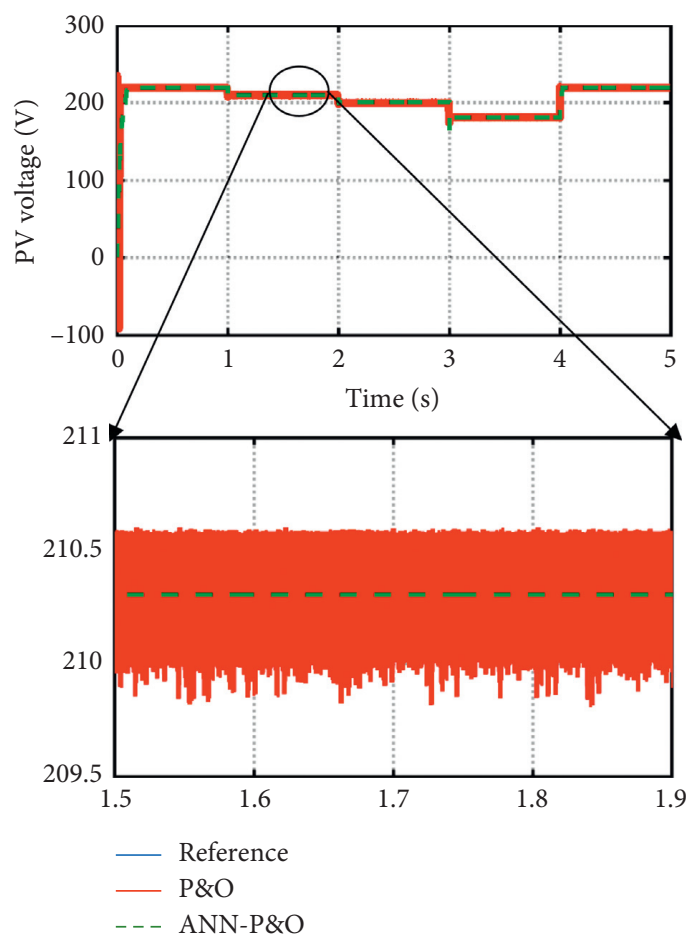

(c)

Figure 13: PV simulation responses under varying temperature. (a) Voltage. (b) Current. (c) Power. 


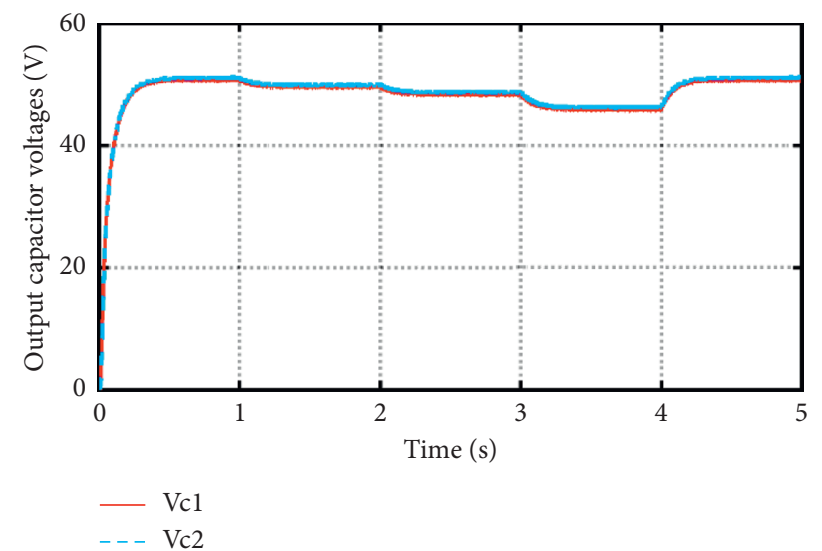

FIgURe 14: Output capacitor voltages of TLBC.

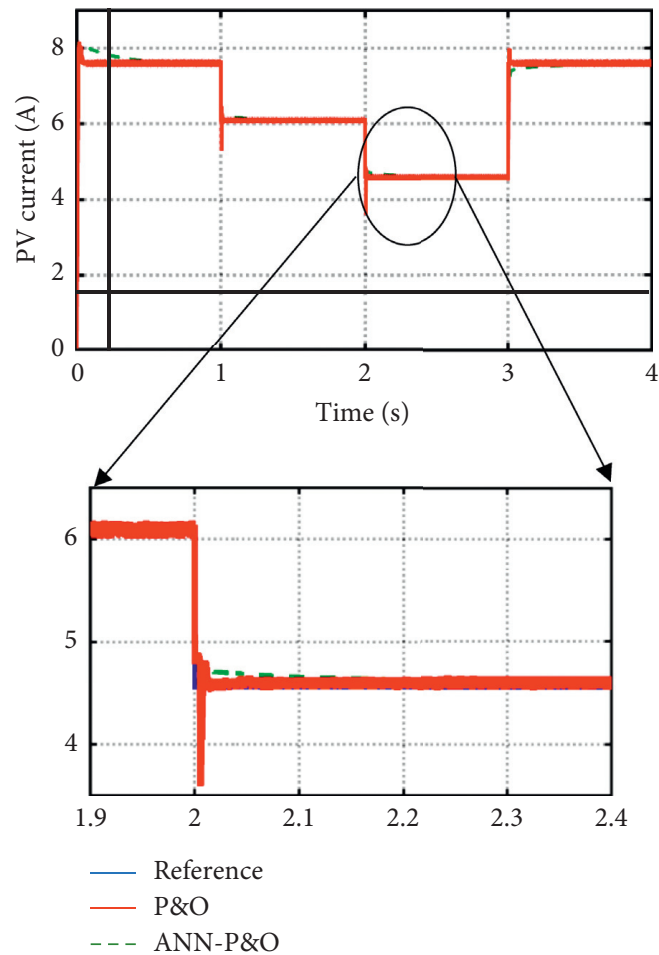

(a)

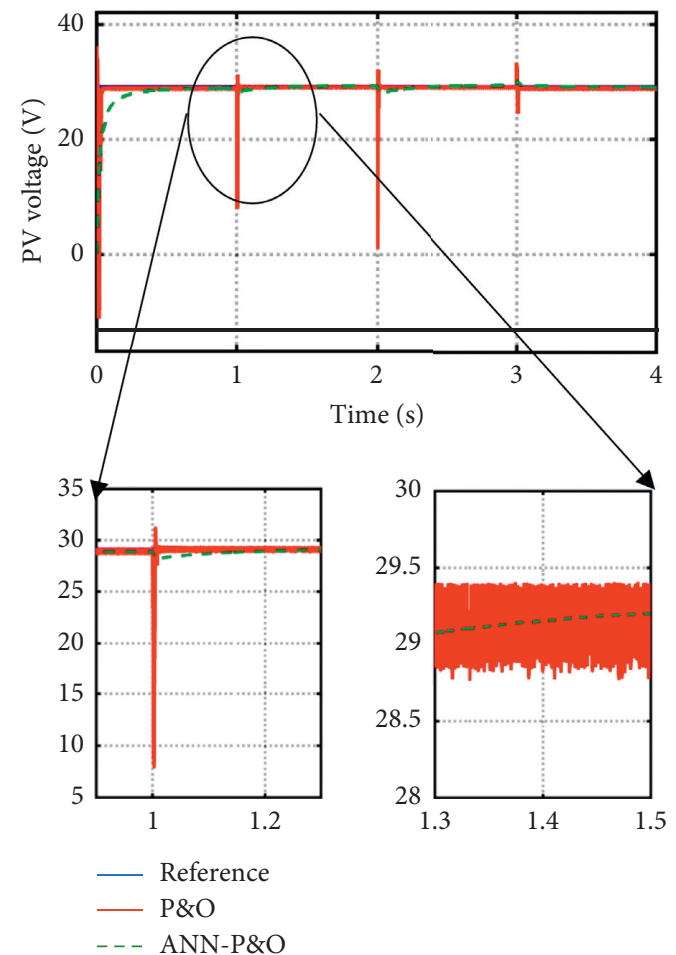

(b)

Figure 15: Continued. 


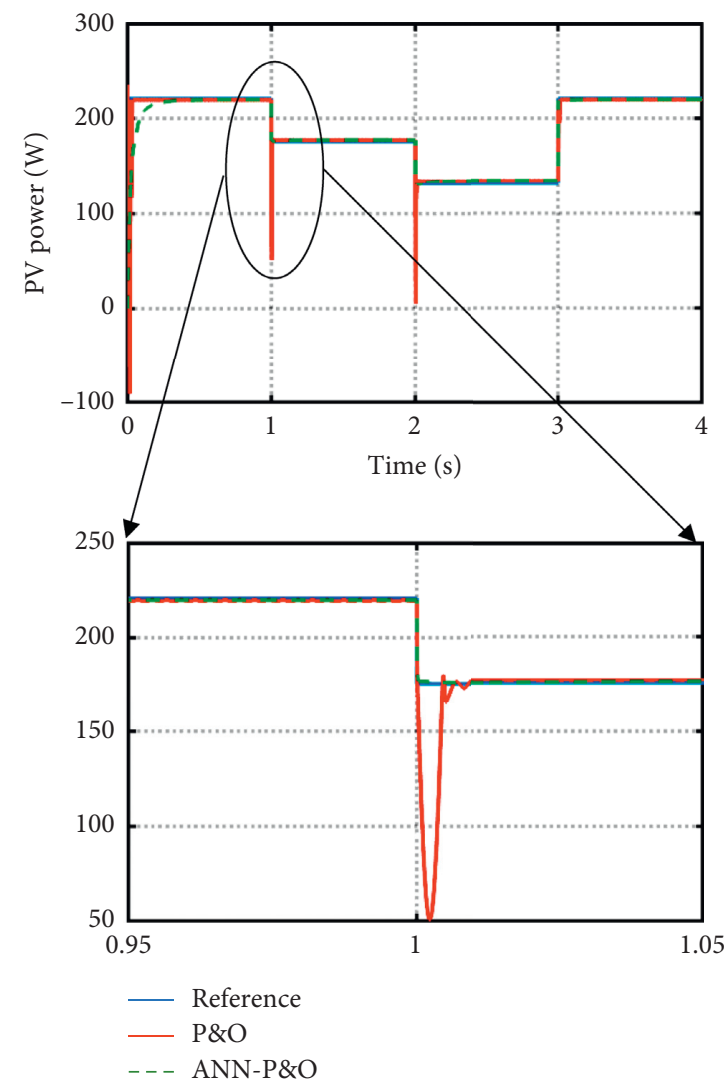

(c)

Figure 15: PV simulation responses under varying irradiance. (a) Current. (b) Voltage. (c) Power.

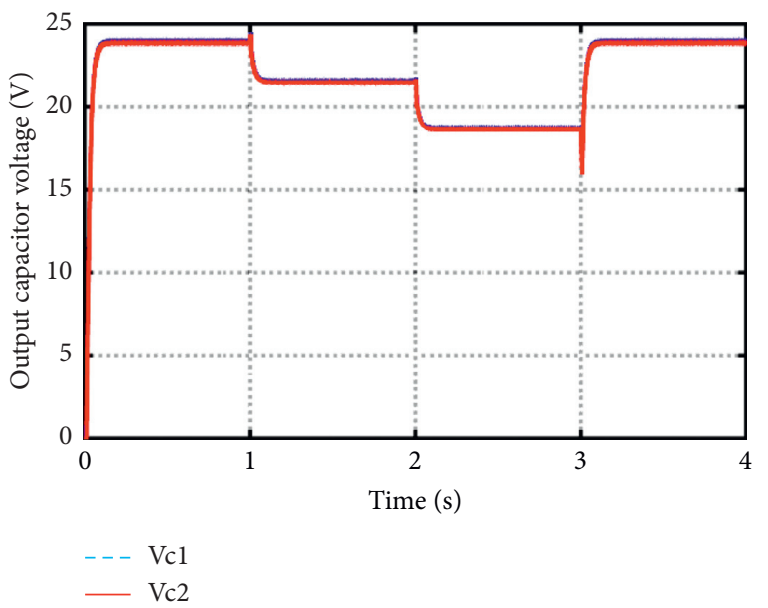

FIGURE 16: Output capacitor voltages of TLB converter. 


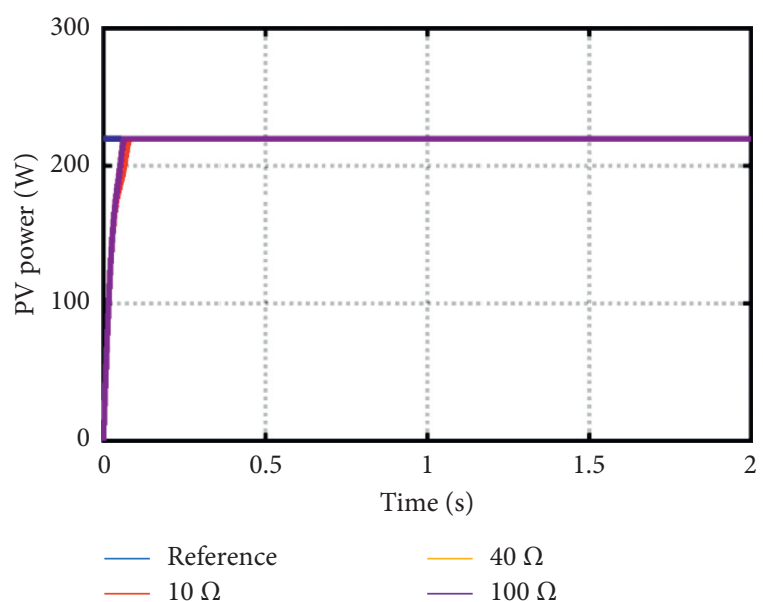

FIGURE 17: PV power responses for variable load $\left(1000 \mathrm{~W} / \mathrm{m}^{2}\right.$ and $\left.25^{\circ} \mathrm{C}\right)$.

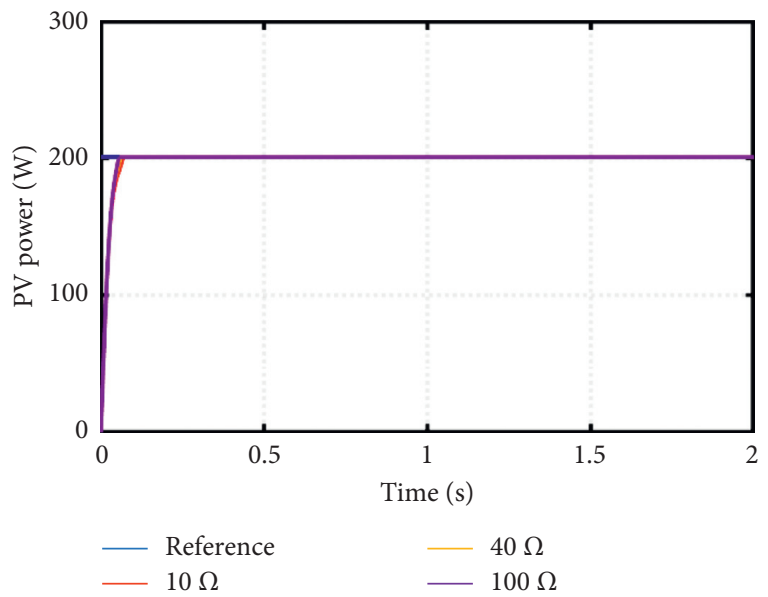

Figure 18: PV power responses for variable load $(1000 \mathrm{~W} / \mathrm{m}$ and $\left.45^{\circ} \mathrm{C}\right)$.

TABle 5: Comparison between the $\mathrm{P} \& \mathrm{O}$ algorithm, ANN, and the proposed method.

\begin{tabular}{lccc}
\hline Methods & References & Power efficiency (\%) & Oscillations \\
\hline P\&O & {$[18,26-28]$} & $94-98$ & High \\
ANN & {$[15,29,30]$} & $92-98$ & Moderate \\
Proposed & - & $99.5-99.8$ & Neglected \\
method & - & &
\end{tabular}

TABLE 6: Comparison between the $\mathrm{P} \& \mathrm{O}$ algorithm and other hybrid methods.

\begin{tabular}{lccc}
\hline Hybrid methods & References & Power efficiency (\%) & Oscillations \\
\hline P\&O-PSO & {$[20]$} & $94-98$ & High \\
P\&O-fuzzy & {$[18]$} & 92 & Moderate \\
P\&O-fuzzy & {$[21]$} & 99.5 & Low \\
$\begin{array}{l}\text { Proposed } \\
\text { method }\end{array}$ & - & $99.5-99.8$ & Neglected \\
\hline
\end{tabular}

\section{Conclusions}

This work aims to develop an intelligent ANN-P\&O algorithm-based MPPT to reduce the oscillations at the MPP using a TLB converter whose duty cycle is controlled to extract maximum power. An artificial neural network was addressed to determine voltage and current at the MPP for any solar irradiance and cell temperature. Based on the divided voltage and current, the conventional P\&O algorithm generated an optimum duty cycle to control the TLB converter. Besides, a PI controller was used to balance the capacitor voltage. The intelligent ANN-P\&O algorithm was validated on Matlab/Simulink under different conditions. The simulation results showed that the proposed technique detects rapidly the variation of irradiation, temperature, and load and makes a correct decision without any oscillation and overshot, contrary to the conventional P\&O algorithm. Hence, the loss of energy is minimized, and energy efficiency is improved.

\section{Data Availability}

No data were used to support this study.

\section{Conflicts of Interest}

The authors declare that they have no conflicts of interest.

\section{References}

[1] IRENA-International Renewable Energy Agency, Renewable Capacity Statistics, IRENA-International Renewable Energy Agency, Abu Dhabi, UAE, 2019, http://www.irena.org.

[2] I. A. Ayad, E. El Warraki, and A. Nouri, "A self-tuning fuzzy PI controller for three-level boost converter," in Proceedings of the 2018 6th international Renewable and sustainable energy conference (IRSEC), pp. 1-6, Rabat, Morocco, December 2018.

[3] C. Balakishan, N. Sandeep, and M. V. Aware, "Design and implementation of three-level DC-DC converter with golden section Search based MPPT for the photovoltaic applications," Advances in Power Electronics, vol. 2015, Article ID 587197, 9 pages, 2015.

[4] V. Yaramasu and B. Wu, "Three-level boost converter based medium voltage megawatt PMSG Wind Energy Conversion Systems," in Proceedings of the Energy Conversion Congress and Exposition (ECCE), pp. 561-567, Phoenix, AZ, USA, Septembre 2011.

[5] G. Zhang, Z. Tian, H. Du, and Z. Liu, "A novel hybrid DC traction power supply system integrating PV and reversible converters," Energies, vol. 11, no. 7, p. 1661, 2018.

[6] C. Kang, W. Wang, W. Li, H. Du, and L. Diao, "Balance midpoint potential control of three-level boost converter for rail transit application," IEEE Access, vol. 7, pp. 47737-47746, 2019.

[7] M. Seyedmahmoudian, B. Horan, T. K. Soon et al., "State of the art artificial intelligence-based MPPT techniques for mitigating partial shading effects on PV systems - a review," Renewable and Sustainable Energy Reviews, vol. 64, pp. 435455, 2016.

[8] S.-S. Alli, S. Jovanovic, P. Poure et al., "MPPT and output voltage control of Photovoltaic systems using a Single-Switch DC-DC converter," in Proceedings of the 2016 IEEE 
International Energy Conference (ENERGYCON), pp. 1-6, Leuven, Belgium, April 2016.

[9] C. H. Tran, F. Nollet, N. Essounbouli et al., "Modeling and simulation of stand alone photovoltaic system using three level boost converter," in Proceedings of the 2017 International Renewable And Sustainable Energy Conference (IRSEC), pp. 1-6, Tangier, Morocco, December 2017.

[10] M. Samadi and S. M. Rakhtala, "Reducing cost and size in photovoltaic systems using three-level boost converter based on fuzzy logic controller," Iranian Journal of Science and Technology, Transactions of Electrical Engineering, vol. 43, no. 1, pp. 313-323, 2019.

[11] S. Motahhir, A. El Ghzizal, S. Sebti et al., "Modeling of photovoltaic system with modified incremental conductance algorithm for fast changes of irradiance," International Journal of Photoenergy, vol. 2018, 13 pages, 2018.

[12] M. E. Başoğlu and B. Çakir, "An improved incremental conductance based MPPT approach for PV modules," Turkish Journal of Electrical Engineering \& Computer Sciences, vol. 23, pp. 1687-1697, 2015.

[13] K. S. Tey and S. Mekhilef, "Modified incremental conductance algorithm for photovoltaic system under partial shading conditions and load variation," IEEE Transactions on Industrial Electronics, vol. 61, no. 10, pp. 5384-5392, 2014.

[14] F. Sedaghati, A. Nahavandi, M. A. Badamchizadeh, S. Ghaemi, and M. Abedinpour Fallah, "PV maximum power-point tracking by using artificial neural network," Mathematical Problems in Engineering, vol. 2012, Article ID 506709, 10 pages, 2012.

[15] C. R. Algarín, D. Sevilla Hern ández, and D. Restrepo Leal, “A low-cost maximum power point tracking system based on neural network inverse model controller," Electronics, vol. 7, no. 1, 4 pages, 2018.

[16] K. Ishaque, Z. Salam, M. Amjad, and S. Mekhilef, "An improved Particle Swarm optimization (PSO)-Based MPPT for PV with reduced steady-state oscillation," IEEE Transactions on Power Electronics, vol. 27, no. 8, pp. 3627-3638, 2012.

[17] M. Seyedmahmoudian, R. Rahmani, S. Mekhilef et al., "Simulation and hardware implementation of new maximum power point tracking technique for partially shaded PV system using hybrid DEPSO method," IEEE Transactions on Sustainable Energy, vol. 6, no. 3, pp. 850-862, 2015.

[18] M. A. A. M. Zainuri, M. A. M. Radzi, A. Che Soh et al., "Development of adaptive perturb and observe-fuzzy control maximum power point tracking for photovoltaic boost $\mathrm{dc}-\mathrm{dc}$ converter," IET Renewable Power Generation, vol. 8, no. 2, pp. 183-194, 2014.

[19] T. Radjai, L. Rahmani, S. Mekhilef, and J. P. Gaubert, "Implementation of a modified incremental conductance MPPT algorithm with direct control based on a fuzzy duty cycle change estimator using dSPACE," Solar Energy, vol. 110, pp. 325-337, 2014.

[20] K. L. Lian, J. H. Jhang, and I. S. Tian, “A maximum power point tracking method based on perturb-and-observe combined with Particle Swarm optimization," IEEE J. Photovoltaics, vol. 4, no. 2, pp. 626-633, 2014.

[21] K. Bataineh and N. Eid, "A hybrid maximum power point tracking method for photovoltaic systems for dynamic weather conditions," Resources, vol. 7, no. 4, p. 68, 2001.

[22] M. A. Sahnoun, H. M. R. Ugalde, J.-C. Carmona, and J. Gomand, "Maximum power point tracking using $\mathrm{P} \& \mathrm{O}$ control optimized by a neural network approach: a good compromise between accuracy and complexity," Energy Procedia, vol. 42, pp. 650-659, 2013.
[23] A. Ayad and E. Elwarraki, "Output voltage control analysis of three-level boost DC-DC converters," in Proceedings of the 2019 4th World Conference On Complex Systems (WCCS), pp. 1-6, Quarzazate, Morocco, April 2019.

[24] L. L. Jiang, D. L. Maskell, and J. C. Patra, "A novel ant colony optimization-based maximum power point tracking for photovoltaic systems under partially shaded conditions," Energy and Buildings, vol. 58, pp. 227-236, 2013.

[25] L. M. Elobaid, A. K. Abdelsalam, and E. E. Zakzouk, "Artificial neural network-based photovoltaic maximum power point tracking techniques: a survey," IET Renewable Power Generation, vol. 9, no. 8, pp. 1043-1063, 2015.

[26] N. Kacimi, S. Grouni, A. Idir, and M. Seghir Boucherit, "New improved hybrid MPPT based on neural network-model predictive control-kalman filter for photovoltaic system," Indonesian Journal of Electrical Engineering and Computer Science, vol. 20, no. 3, p. 1230, 2020.

[27] Y.-H. Liu, C.-L. Liu, J.-W. Huang, and J.-H. Chen, "Neuralnetwork-based maximum power point tracking methods for photovoltaic systems operating under fast changing environments," Solar Energy, vol. 89, pp. 42-53, 2013.

[28] B. Bendib, H. Belmili, and F. Krim, "A survey of the most used MPPT methods: conventional and advanced algorithms applied for photovoltaic systems," Renewable and Sustainable Energy Reviews, vol. 45, pp. 637-648, May 2015.

[29] C. Ben Salah and M. Ouali, "Comparison of fuzzy logic and neural network in maximum power point tracker for PV systems," Electric Power Systems Research, vol. 81, no. 1, pp. 43-50, 2011.

[30] B. C. Kok, H. H. Goh, and H. G. Chua, "Optimal power tracker for stand-alone photovoltaic system using artificial neural network (ANN) and Particle Swarm optimisation (PSO)," in Proceedings of the International Conference on Renewable Energies and Power Quality (ICREPQ'12), pp. 440-445, Madrid, Spain, June 2012. 